\title{
Araç Kuzeydoğusu (Kastamonu) Erken Eosen Sığ-Denizel Bentik Foraminifer Topluluğu ve Paleoekolojik Yorum
}

\author{
Shallow Marine Benthic Foraminifera Assemblage of the Early Eocene Succession in the \\ Northern Araç (Kastamonu) and Paleoecological Interpretation \\ Nazire ÖZGEN ERDEM ${ }^{1}$, M. Yasin CANBOLAT ${ }^{2}$, Derya SINANOĞLU ${ }^{3}$ \\ ${ }^{1}$ Cumhuriyet Üniversitesi, Jeoloji Mühendisliği Bölümü, 58140 Sivas \\ (nozgen@cumhuriyet.edu.tr) \\ ${ }^{2}$ Nevşehir Hacı Bektaş Veli Üniversitesi, Jeoloji Mühendisliği Bölümü, 50300 Nevşehir \\ ${ }^{3}$ Batman Üniversitesi, Jeoloji Mühendisliği Bölümü, 72000 Batman
}

\section{ÖZ}

Bu çalışmada, Araç kuzeydoğusunda (Kastamonu) Erken Eosen yaşlı Soğanlı Formasyonu paleontolojik ve paleoekolojik açıdan incelenmiştir. Bu istif; gri yer yer sarımsı renkli, gevşek dokulu, bol iri bentik foraminiferli killi kireçtaşlarından oluşur. Killi kireçtaşlarının alt seviyelerinde Alveolina ve Orbitolites gibi porselen kalker kavkılı foraminiferler ve dascylad algler baskındır. İstifin üst kesimleri ise Assilina ve Nummulites gibi hyalin kalker kavkılı foraminiferlerin bolluğu ile karakterize olur. Ölçülü kesit boyunca; Idalina sinjarica Grimsdale, Glomalveolina lepidula Schwager, Alveolina cemali Sirel \& Acar, A. rotundata kazancii Sirel \& Acar, A. erki Acar, A. ankarensis Sirel, A. pieroi Sirel \& Acar, Lockhartia conditi (Nuttall), L. tipperi (Davies), Orbitolites complanatus Lamarck, Cyclopertorbitolites tokerae ÖzgenErdem, Assilina spinosa Davies \& Pinfold, Nummulites sp., Cribrobulimina sp., Kathina sp., Neorotalia sp., Triloculina sp. fosil topluluğu tanımlanmıştır. Tanımlanan bu fosil topluluğu, kesit alınan bölgedeki istif için Erken İpresiyen yaşını işaret eder. Ayrıca bu topluluğa göre, birimin çökelimi korunaklı, sakin sı̆̆ ortamda başlamış ve düşük enerjili sığ denizel ortamda devam etmiştir.

Anahtar Kelimeler: Araç (Kastamonu), bentik foraminifer, Eosen, erken İpresiyen,

\section{ABSTRACT}

Soğanlı Formation of Early Eocene age in the northeastern of Araç (Kastamonu) has been investigated in order to determine their paleontology and palaeoecology. The sequence consists of gray, yellowish, clayey limestone, rich in larger benthic foraminifers. The lower parts of clayey limestone are dominated by porcellaneous foraminifera such as Alveolina and Orbitolites and by dascylad algae. The top of the section is characterized by hyaline calcareous foraminifers such as Assilina and Nummulites. Idalina sinjarica Grimsdale, Glomalveolina lepidula Schwager, A. cemali Sirel \& Acar, A. rotundata kazancii Sirel \& Acar, 
A. erki Acar, A. ankarensis Sirel, A. pieroi Sirel \& Acar, Lockhartia conditi (Nuttall), L. tipperi (Davies), Orbitolites complanatus Lamarck, Cyclopertorbitolites tokerae Özgen-Erdem, Assilina spinosa Davies \& Pinfold, Nummulites sp., Cribrobulimina sp., Kathina sp., Neorotalia sp., Triloculina sp. have been decribed along the section. The distribution of the larger benthic foraminifera indicates Early Eocene age. According to these assemblages, we interpret that deposition of the unit started in a restricted shallower environment and continued in a shallow high energy environment.

Key Words: Araç (Kastamonu), benthic foraminifera, early Ypresian, Eocene

\section{GíRiş}

Çalışmanın gerçekleştirildiği bölge, 1/25.000 ölçekli Kastamonu F30-c1 paftasında bulunan Araç (Kastamonu) ilçesinin kuzeydoğusunda yer alır (Şekil 1). Araç ve civarında yapılan öncel çalışmalar çoğunlukla; genel jeoloji, petrol jeolojisi, metamorfizma ve metalik maden amaçlıdır (Eren, 1979; Yılmaz, 1983; Yılmaz ve Tüysüz, 1984; Aydın ve diğ, 1986; Boztuğ, 1992; Barkurt ve diğ., 1990; Şengün ve diğ., 1990; Aydal, 2000; Göncüoğlu ve diğ., 2014). Buna karşılık, Kastamonu ve yakın civarında kapsamı paleontoloji olan çalışmalara daha az sayıda rastlanılmaktadır (Dizer, 1953; Sağular ve diğ., 1991; Y1ldız ve diğ., 1997; Tuzcu ve Babayiğit, 1998; Tunoğlu ve Ertekin, 2005; Tunoğlu ve Bardet, 2006). Özgen- Erdem ve diğ., (2005) Kastamonu civarındaki altı lokalitede, Paleosen-Eosen bentik foraminifer topluluklarını tanıtmışlardır. Bu çalışmayı takiben, inceleme alanının doğusunda yer alan Tosya kuzeyindeki İlerdiyen yaşlı birimde alveolinid ve soritid formlar tanımlanmıştır (Özgen-Erdem, 2008, 2010).
Bu çalışmanın odaklandığıA Araç civarında, öncel araştırmalarda sı̆̆ denizel istifler için farklı yaşlar kullanılmıştır. Paleontolojik tanımlamanın yapılmadığı, değişik amaçları kapsayan incelemelerde bu birim için Eosen çökelleri ifadesi kullanılmıştır (Aydal, 2000; Göncüoğlu ve diğ., 2012, 2014). Aydın ve diğ. (1986) DadayDevrekani hattı boyunca yaptıkları çalışmada, Araç kuzeyindeki sı̆̆ denizel birim için Soğanlı formasyonu adlamasını kullanmış ve saptanan Alveolina ve Orbitolites türlerine dayanarak Erken-Orta Eosen yaşını önermişlerdir. Boztuğ (1992), inceleme alanının batısındaki DadayDevrekani masifini konu alan çalışmasında, sı̆̆ denizel ve bol fosilli Soğanlı Formasyonu için, Nummulites beaumonti ve Assilina exponens türlerine dayanarak Orta Eosen yaşı verilmiştir. Araç civarındaki Eosen istifi, Barkurt ve diğ., (1990) tarafindan Araç formasyonu olarak adlandırılmış ve tanımlanan Nummulites'lere göre Lütesiyen yaşı verilmiştir. 


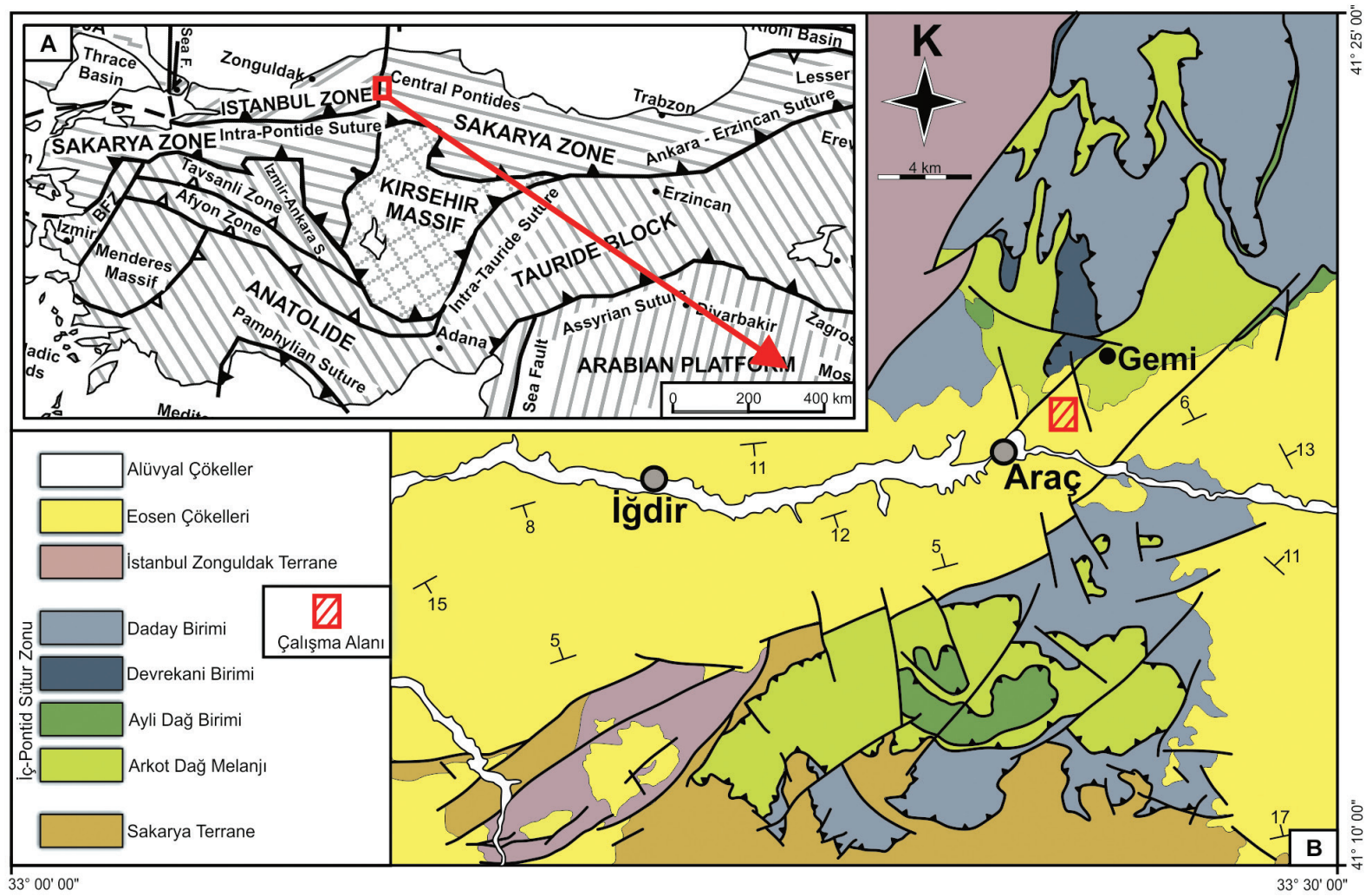

Şekil 1. Çalışma alanını gösteren jeoloji haritası (Okay ve Tüysüz, 1999- A; Göncüoğlu ve diğ., 2014- B)

Figure 1. Geological map of study area (from Okay and Tüysüz, 1999- A; Göncüoğlu et al., 2014- B)

$\mathrm{Bu}$ çalışmanın amacı, Araç kuzeydoğundaki Eosen yüzleğinin porselen kalker kavk1lı iri bentik foraminiferleri içeren seviyelerindeki türleri tanımlamak ve birimin bu düzeylerinin yaş konağını detaylı olarak belirlemektir. İstifin bol nummulitid içeren düzeyleri bu çalışmanın dışında bırakılmıştır. $\mathrm{Bu}$ amaç doğrultusunda yüzlekten bir ölçülü kesit alınmış ve toplam 30 sistematik ve 40 yönlü ince kesit üzerinde iri bentik foraminiferlerin tanımlanması yapılmıştır. Çalışma örnekleri Cumhuriyet Üniversitesi, Jeoloji Mühendisliği Bölümü Paleontoloji laboratuvarında depolanmaktadır.

\section{STRATIGRAFI}

Pontid-İçi Kenedi içerisinde yer alan Araç ilçesi ve yakın civarında yüzlek veren, fosilli kireçtaşı ve kırıntılılardan oluşan Eosen birimi için çoğunlukla Soğanlı Formasyonu adlaması kullanılmış ve bu adlamaya Türkiye Stratigrafi Komitesi'nin Batı Karadeniz Bölgesi Litostratigrafi Birimleri-1 (Tüysüz ve diğ., 2004) serisinde de yer verilmiştir. Soğanlı Formasyonu ilk kez Güven (1977) tarafından iki üyeye ayırtlanarak tanımlanmış ve Geç Eosen yaşı önerilmiştir. Formasyonun Akyar üyesi Saner ve diğ. (1979) tarafindan Soğanlı kireçtaşı olarak tanımlanmıştır. Araştırmacılar bu düzeylerin Erken-Orta Eosen yaşlı olduğunu ifade etmişlerdir. Yergök ve diğ., (1987) bu düzeyler 
için Soğanlı Formasyonu adlamasını kullanmış ve Lütesiyen yaşı önermişlerdir. Formasyon, bölgede yer yer Üst Kretase yaşlı ofiyolitik melanj ve orta Jura yaşl1 metamorfitler üzerine gelir (Aydal, 2000; Göncüoğlu ve diğ., 2012). Kuvaterner yaşı alüvyonlar, çalışmanın yapıldığ 1 bölgedeki en genç birimi oluşturur.

\section{Araç Ölçülüi Stratigrafi Kesiti}

Kesit, 1/25.000 ölçekli Kastamonu F30 c1 paftasındaki Araç ilçesinin yaklaşı $8 \mathrm{~km}$ kuzeydoğusundaki Gemi Köyü yakınından alınmıştır (Şekil 1). Toplam 45 metre kalınlık ölçülmüş ve 30 örnek üzerinde detaylı çalışmalar gerçekleştirilmiştir (Şekil 2).

İstifin alt kesimlerinde hakim litoloji, gri yer yer sarımsı renkli, gevşek dokulu az killi kireçtaşlarıdır. Kireçtaşları çoğunlukla mikritik bağlayıcı içinde iri bentik foraminifer kavkılarının ve dascylad alglerin baskın olarak yeraldığ istiftaşı fasiyesi ile temsil olur. İlk 6 örneğe denk gelen bu seviyelerde (1-10 m), İ. sinjarica, G. lepidula, A. cemali, A. erki, A. rotundata kazancii, L. conditi, O. complanatus, C. tokerae, Cribrobulimina sp., Lockhartia sp., Kathina sp., Nummulites sp. tanımlanmıştır. Takip eden 12. metrede (7. Örnek) bu topluluğa ek olarak $A$. ankarensis ve L. tipperi gözlenmiştir. Kesitin 16. metresinden itibaren, Ass. spinosa türü ilk kez görünmeye başlar. Tanımlanan bu topluluğa dayandırılarak istifin bu bölümlerine erken İpresiyen (orta İlerdiyen'in altı) yaşı verilmiştir. Litolojinin belirgin bir değişiklik göstermediği üst seviyelere doğru killi kireçtaşları yine mikritik bağlayıcının hakim olduğu vaketaşı fasiyesinden oluşur. Bu düzeylerde $\dot{I}$. sinjarica, G. lepidula, A. ankarensis, A. rotundata kazancii, A. pieroi, L. conditi, L. tipperi, O. complanatus, C. tokerae, Ass. spinosa, Glomalveolina sp., Alveolina sp., Cribrobulimina sp., Neorotalia sp., Nummulites sp., tanımlanmıştır. İstifin bu bölümünde (yaklaşık $35 \mathrm{~m})$, A. pieroi görünmeye başlar. Araç kesitinin en üst düzeylerinde alveolinid ve soritid formların baskınlığının yerini nummulitid formlar alır. Özellikle Ass. spinosa sayıca fazlalaşır (3740 metreler aras1). Porselen kalker formlardan sadece $O$. complanatus gözlenir. Kesitin bu son seviyelerinde $O$. complanatus (oldukça az), Ass. spinosa, L. conditi, Nummulites sp., Neorotalia sp., Cribrobulimina sp. tanımlanan formlardır. $\mathrm{Bu}$ topluluk istifin üst kesimlerinin Erken İpresiyen (orta İlerdiyen'in üstü) yaşlı olduğunu işaret eder. 


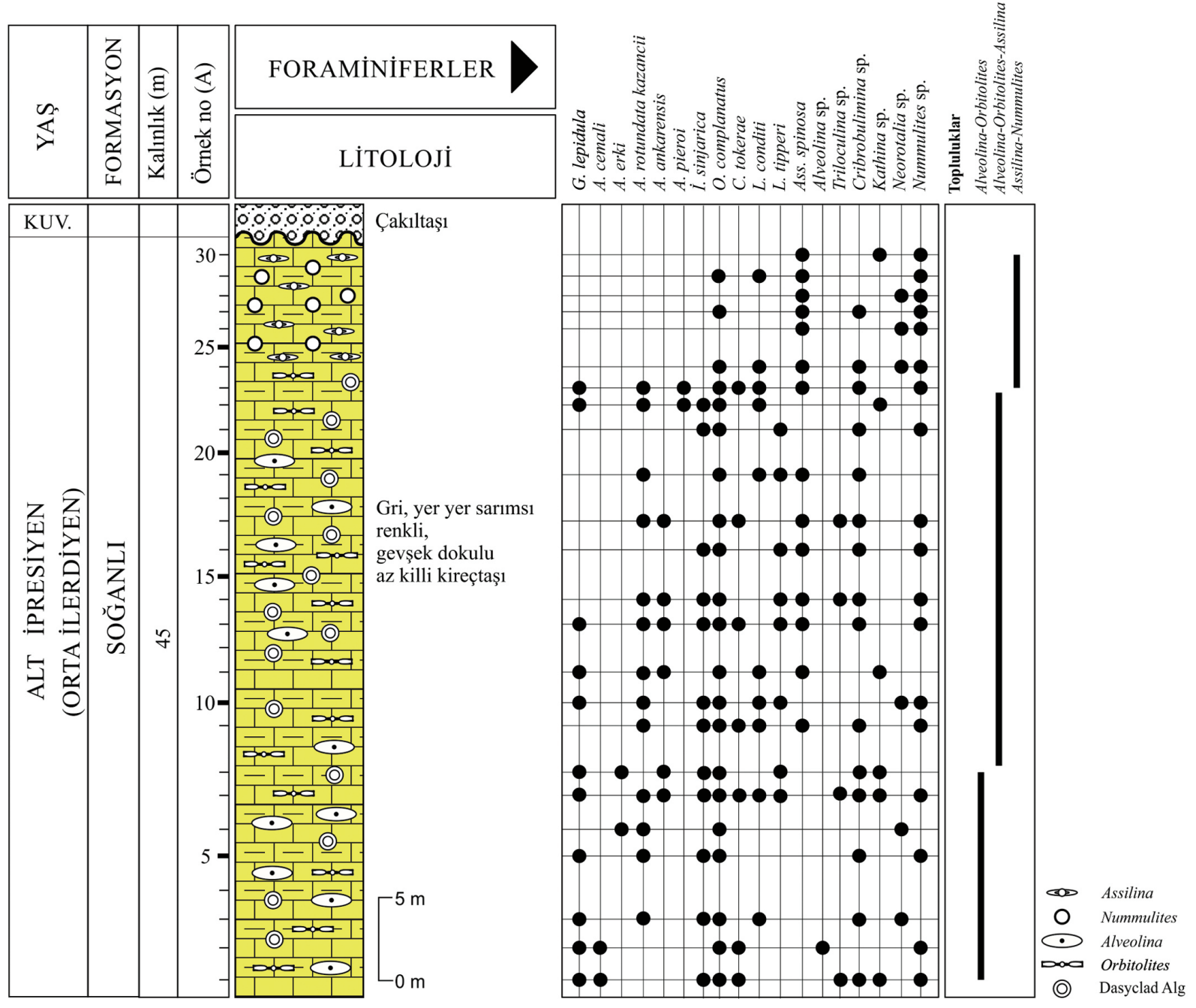

Şekil 2. Araç stratigrafi kesitinde bentik foraminiferlerin dağılımı.

Figure 2. Distribution of benthic foraminifera in Araç stratigraphic section

\section{BIIYOSTRATİGRAFİ VE TARTIŞMA}

Porselen kalker kavk1lı iri bentik foraminiferlerle temsil olan Alt Eosen birimleri Anadolu'da sinırlı yayılım sunarlar. Eskişehir güneyinde yer alan Seyitgazi ve çevresinde benzer fosil topluluğuna sahip Alt Eosen çökelleri saptanmış ve porselen kalker kavk1lı iri bentik foraminiferleri ve dascylad algleri detaylı olarak çalışılmıştır (Özgen Erdem ve diğ., 2007). Bu birim oldukça iyi korunmuş dascylad alg topluluğuna sahiptir (Özgen Erdem \& Radoicic, 2009; Radoicic \&
Özgen Erdem, 2011; Özgen Erdem \& Radoicic, 2014 ve Radoicic \& Özgen Erdem, 2014). Tosya kuzeyinde (Kastamonu) alveolinid ve soritid gibi porselen kalker formların baskın olduğu İlerdiyen çökellerinin bu formları Özgen Erdem ve diğ., (2005) ve Özgen Erdem $(2008,2010)$ tarafindan tanımlanmıştır.

Araç kuzeydoğusunda yüzlek veren Alt Eosen çökelleri fauna içeriği ile Tosya kuzeyi ve Seyitgazi güneyindeki istiflerle büyük benzerlik sunar. Ancak çalışma alanının Alt Eosen 
seviyelerindeki kısmen iri bentik foraminiferler, çoğunlukla ise dascylad algler iyi korunmamıştır. Araç ölçülü kesiti boyunca 3 bentik foraminifer topluluğu belirlenmiştir. Kesitin en üst seviyesini oluşturan Assilina ve Nummulites'lerin baskın olduğu topluluk dişında tüm kesit boyunca bu bentik foraminifer topluluklarına dascylad algler eşlik eder.

\section{Alveolina-Orbitolites Topluluğu}

Kesitin (1-16 m) alt seviyelerinde gözlenen bu topluluk alveolinid ve soritid formların baskınlığ ile karakterize olur. Kesitin, ilk 10 metrelik kesiminde $G$. lepidula, A. cemali, A. rotundata kazancii, A. erki, O. complanatus baskın türler olarak gözlenmektedir. Toplulukla birlikte bulunan C. tokerae, L. conditi, I. sinjarica, Cribrobulimina sp., Triloculina sp., Kathina sp., Neorotalia sp., Nummulites sp. sayısal olarak nispeten daha azdır. Kesitin 12. metresinden itibaren A. ankarensis ve L. tipperi gözlenmeye başlar.

Kesitin tüm seviyelerinde gözlenen G. lepidula türü Tosya kuzeyinde ve Seyitgazi güneyindeki istiflerde erken- orta İlerdiyen'de görünmektedir (Özgen Erdem, 2008, 2010). $\mathrm{Bu}$ tür, Bünyan (Kayseri) bölgesinde erken İlerdiyen'de gözlenmiştir. G. lepidula'nın beraber bulunduğu $A$. cemali, Bünyan ve Polatlı' da erkenorta İlerdiyen'de (SBZ 6-7) tanımlanmıştır (Sirel \& Acar, 2008). Bu toplulukta tanımlanan A. erki ise Polatlı (Ankara) orta-geç İlerdiyen'inde (SBZ 7-9) A. montanarii, A. subpyrenaica, A. laxa, A. minervensis topluluğu ile birlikte bildirilmiştir (Sirel \& Acar, 2008). Topluluk boyunca bol olarak gözlenebilen $A$. rotundata kazanci ve $A$. ankarensis Polatlı yöresinde orta İlerdiyen (SBZ 7-8) yaşlı düzeylerde tanımlanmıştır (Sirel, 1976; Sirel \& Acar, 2008). A. ankarensis Sakarya kesitinde (Polatl1); A. blumenthali, A. avellana, $A$. ellipsoidalis ve $A$. pisiformis ile birlikte SB 7-8 zonlarında (orta İlerdiyen) gözlenmiştir (Sirel,
2015). Kesitin ilk seviyelerinde ortaya çıkan ve tüm Araç kesiti boyunca da gözlenen $L$. conditi geç Hottinger (2014) tarafindan Tanesiyen - orta İlerdiyen (SBZ 4-8) aralığında gösterilmiştir. $L$. tipperi ise orta İlerdiyen- alt geç İlerdiyen (SBZ 7-9) aralığını temsil eder (Hottinger, 2014). Pakistan kuzeyinde $L$. conditi ve $L$. tipperi, erken Eosen yaşlı düzeylerde bildirilmiştir (Ghazi ve diğ., 2010). Kesit tabanından itibaren gözlenen Cyclopertorbitolites tokerae tip lokalitesi olan Seyitgazi güneyinde orta İlerdiyen-erken Küviziyen ve Tosya kuzeyinde ise orta İlerdiyen düzeylerinde tanımlanmıştır.

\section{Alveolina-Orbitolites-Assilina Topluluğu}

Araç kesitinin bu seviyelerinde (16-37 m) gözlenen topluluk, bileşenleri bakımından AlveolinaOrbitolites topluluğuna benzerlik sunar. Ancak bu seviyelerde Ass. spinosa ortaya çıkar ve kesitin üst seviyelerine doğru sayısal olarak artış gösterir. $A$. rotundata ve $A$. ankarensis bu düzeylerin baskin alveolinleridir. Kesitin 35-37. metrelerinde sferik bir alveolina olan $A$. ankarensis oldukça azalmaya, buna karşın uzamış ve floskulinleşmiş alveolinlerden A. pieroi artmaya başlamıştır. Soritidler ise $O$. complanatus ve $C$. tokerae ile temsil olur. Ancak tüm kesit boyunca $O$. complanatus baskındır. Bu toplulukta, L. conditi ve $L$. tipperi belirgin bir artış sunarlar.

Araç kesitinin üst seviyelerine doğru ortaya çıkan A. pieroi Sirel \& Acar, ilk tanımlandığ1 Sakarya kesitinde (Polatlı) orta İlerdiyen'in (SBZ8) üst kesimlerinde ve üst İlerdiyen'de (SBZ 9) bildirilmiştir (Sirel \& Acar, 2008).

\section{Assilina-Nummulites Topluluğu}

Kesitin en üst düzeylerinde gözlenen bu toplulukta özellikle Ass. spinosa ve Nummulites sp. baskındır. $\mathrm{Bu}$ topluluğa Lockhartia conditi ve Neorotalia 
sp. eşlik eder. Alveolinidler ve soritidler oldukça azalmıştır. Ass. spinosa, kuzey Pakistan'da Erken Eosen yaşlı düzeylerde tanımlanmıştır (Ghazi ve diğ., 2010). L. conditi ise Ankara-Haymana (Sirel, 1976) ve Namrun-İçel'de (Avşar, 1992) Erken Eosen yaşlı düzeylerde saptanmıştır.

\section{ORTAMSAL YORUM}

İri bentik foraminiferlerin bazı gruplarında (alveolinid ve nummulitid gibi) kavkının yapısı, şekli ve çap/kalınlık oranları paleoekolojik koşullarınyorumlanmasındaönemliverilersunarlar (Hottinger, 1960, 1977, 1997; Lutherbacher, 1970; Hottinger ve Dreher, 1974; Larsen, 1976; Hallock ve Glenn, 1986). Güncel foraminiferlerin incelendiği ekolojik çalışmalarda; suyun enerjisi, 1ş1k durumu ve derinlik faktörlerinin özellikle kavk1 şekliyle ilişkili olduğu gözlenmiştir. Enerjinin ve 1şı̆̆ın yüksek olduğu ortamlarda daha merceksi, şişkin formların yaşadığ 1 ; enerjinin ve 1şığın azaldığ 1 ancak derinliğin arttığı koşullarda ise daha basık ve uzamış bireylerin baskın olduğu belirtilmiştir (Hallock ve Glenn, 1986). Porselen kalker kavkılı formlar ise düşük enerjili ortamlarının tipik formları olarak gösterilmektedir (Grenier, 1969; Murray, 1973; Reiss ve Hottinger, 1984). Alveolina'ların sferik olanlarının genellikle lagün ortamını işaret ettiği (Lutherbacher, 1970) buna karşın oval ve uzamış formlarının ise normal tuzlulukta, sınırlı ve oldukça sı̆̆ denizel ortamı yansıttıkları belirtilmiştir (Lutherbacher, 1970; Hottinger, 1960). Bu çalışmalarda, soritid foraminiferlerden Orbitolites ve Opertorbitolites cinslerinin de aynı ortam koşullarını paylaştıkları bildirilmiştir. Araç ölçülü kesitinde, Erken İpresiyen'in alt kesimleri (alt orta İlerdiyen), alveolinid ve orbitolitid formların baskınlığı ile tipiktir (Şekil 3A). Bu seviyelerdeki Alveolina topluluğunda çoğunlukla küçük ancak uzamış formlar olan $A$. rotundata kazancii bireyleri baskindir.
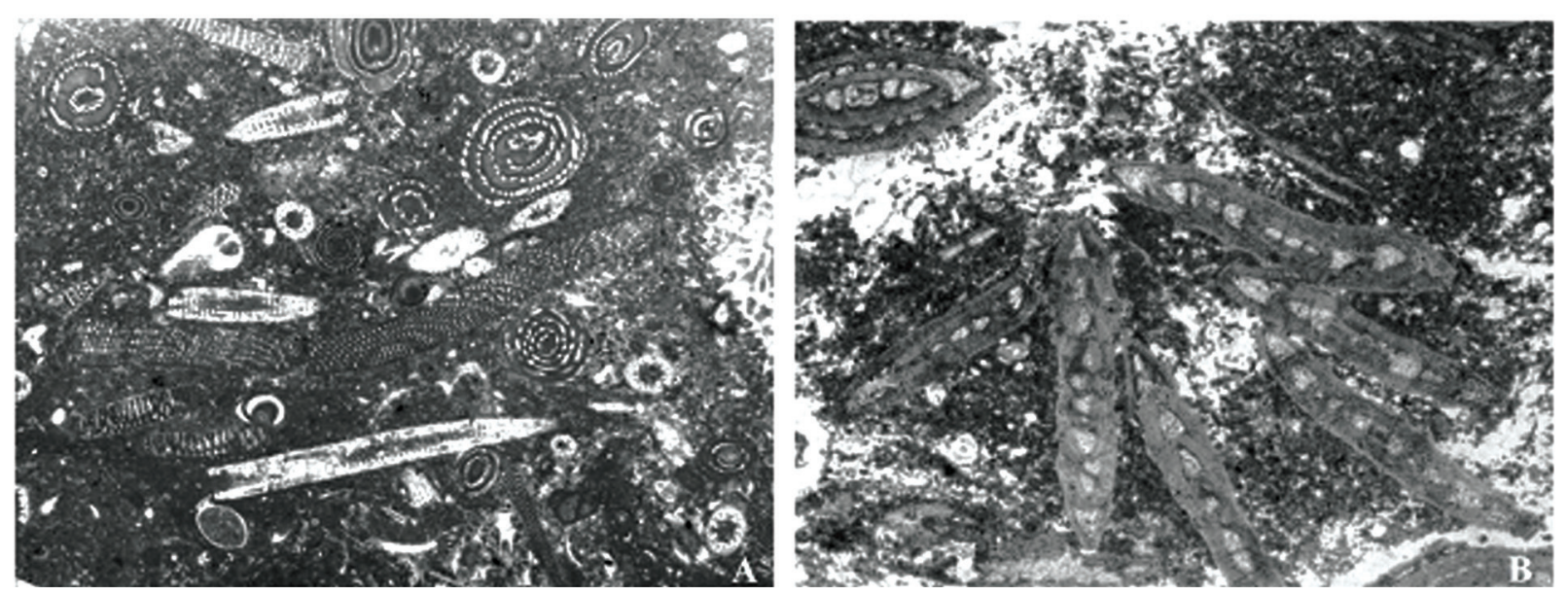

Şekil 3. Alveolina ve Orbitolites'li seviyelerden (A) ve Assilina'lı seviyelerden (B) görünüm

Figure 3. The view of levels with Alveolina and Orbitolites (A) and with Assilina (B). 
Erken İpresiyen'in üst kesimlerinde baskın formlar çoğunlukla Assilina ve kısmen de Nummulites bireyleridir (Şekil 3B). Merceksi Nummulites ve granüllü Assilina bireylerinin, alt fotik zona yakın, düşük su enerjili sı̆̆ denizel ortamı yansıttıkları ifade edilmiştir (Accordi ve diğ., 1998; Scheibner ve diğ., 2007). Tanımlanan bu topluluk, Araç kuzeydoğusunda Erken Eosen (erken İpresiyen) istifinin korunaklı ve oldukça sığ denizel ortam koşullarında çökelmeye başladığını, sonrasında ise nispeten daha derin, düşük enerjili sığ ortamda çökelmeye devam ettiğini işaret eder.

\section{SONUÇLAR}

Araç kuzeydoğusunda yapılan bu çalışmada, Alt Eosen yaşlı Soğanlı Formasyonu'nun alt kesiminden alınan ölçülü kesit üzerinde detaylı paleontolojik incelemeler yapılmıştır.

Ölçülü kesit boyunca çoğunlukla killi kireçtaş1 litolojisinin devamlılık sunduğu istifte özellikle porselen kalker kavkılı bentik foraminiferlerin ve dascylad alglerin bolluğu karakteristiktir. İstifin alt ve orta kesimlerinde iki bentik foraminifer topluluğu tanımlanmıştır. Alveolina - Orbitolites topluluğu ve Alveolina - Orbitolites - Assilina topluluğu olarak adlandırılan bu toplulukların tanımlandı $\breve{g} 1$ seviyelerde; I. sinjarica, G. lepidula, A. cemali, A. erki, A. rotundata kazancii, A. ankarensis, A. pieroi, Lockhartia conditi, L. tipperi, Orbitolites complanatus, Cyclopertorbitolites tokerae, Ass. spinosa, Cribrobulimina sp., Kathina sp., Nummulites sp. tanımlanmıştır. Kesitin en üst kesimlerini oluşturan Assilina-Nummulites topluluğunda, baskın olarak Ass. spinosa ve Nummulites'ler saptanmıştır. Tanımlanan bu bentik foraminifer toplulukları istifin Erken İpresiyen (Orta İlerdiyen) yaşlı olduğunu ve başlangıçta oldukça sığ ve korunaklı denizel ortamda, sonrasında ise düşük enerjili ve nispeten daha derin bir ortamda çökeldiğini gösterir.

\section{EXTENDED SUMMARY}

Lower Eocene units, which are represented with porcellaneous larger benthic foraminifera, offer limited spread in Anatolia. Lower parts of Soğanl formation, which outcrops at and in the near vicinity of Araç district (Kastamonu) and is formed of fosilliferous limestones and debris, contains levels dominated by porcellaneous forms. The present study is focused to describe the present species of benthic foraminifera and the depositional setting of the Early Eocene Soğanl Formation. A stratigraphic section was studied. The Araç section is located near the village of Gemi, about $8 \mathrm{~km}$ northeast of the Araç town. The unit is represented by gray, yellowish, clayey limestone, rich in larger benthic foraminifers. These larger benthic foraminiferal species principally belong to the following genera in the lower part of the section: Glomalveolina, Alveolina, Orbitolites, Cyclopertorbitolites, Lockhartia and dascylad algae. Upwards, succession is characterized by hyaline perforated foraminifers such as Assilina and Nummulites. The most diagnostic species include Idalina sinjarica Grimsdale, Glomalveolina lepidula Schwager, A. cemali Sirel \& Acar, A. rotundata kazancii Sirel \& Acar, A. erki Acar, A. ankarensis Sirel, A. pieroi Sirel \& Acar, Lockhartia conditi (Nuttall), L. tipperi (Davies), Orbitolites complanatus Lamarck, Cyclopertorbitolites tokerae ÖzgenErdem, Assilina spinosa Davies \& Pinfold. These fossil assemblages suggest Early Eocene age for these levels of the Soğanl Formation. Mainly three larger foraminiferal associations were distinguished within the sections, one (AO) dominated by Alveolina and Orbitolites, two (AOA) dominated by Alveolina, Orbitolites and Assilina, 
the other (AN) by Assilina and Nummulites. A detailed examination of these assemblages reveals that deposition of the unit started in a restricted shallower environment and continued in a shallow low energy environment.

\section{DEĞINIILEN BELGELER}

Avşar, N., 1992. Namrun (İçel) yöresi Paleojen bentik foraminifer faunas1. MTA Dergisi, 114, 127-144.

Aydal, D., 2000. Araç masifinin jeodinamik süreçleri, Batı Pontidler, Kastamonu, Türkiye. MTA Dergisi, 122, 73-94.

Aydın, M., Şahintürk, Ö., Serdar, H.S., Özçelik, Y., Akarsu, İ., Üngör, A., Çokuğraş, R., and Kasar, S., 1986. The geology of the area between Ballidag and Çangaldağ (Kastamonu). Bulletin of the Geological Society of Turkey, 29 (2), 1-16.

Barkurt, M.Y., Bilginer, E., Pehlivan, Ş., Örçen, S., Can B., Dağer, Z., Bilgi, C., Karabıyıkoğlu, ve M., Süer, T., 1990. Kastamonu-Araç ve güneyinin jeolojisi. MTA Rapor no: 9079.

Boztuğ, D., 1992. Daday-Devrekani masifi güneybatı kesiminin litostratigrafi birimleri ve Tektoniği. MTA Dergisi 114, 1-20.

Dizer, A., 1953. Kastamonu nummulitiğinin paleontolojik etüdü. Istanbul Üniversitesi Fen Fakültesi Mecmuas1, B, 18/3-4, 207-299.

Eren, R. H., 1979. Kastamonu Taşköprü bölgesi metamorfitlerinin jeolojik, petrografik etüdü. İTÜ. Mim. Müh. Fak. Fen Bil. Ens., Doktora tezi, 143 s.

Ghazi, S., Ali, A., Hanif, T., Sharif, S. and Arif, S.J., 2010. Larger Benthic Foraminiferal Assemblage from The Early Eocene Chor Gali Formation, Salt Range, Pakistan. Geol. Bull. Punjab Univ. 45, 8391.

Göncüoğlu, M.C., Marroni, M., Sayit, K., Tekin, U.K., Ottria, G., Pandolfi, L. and Ellero, A., 2012. The Ayli Dağ ophiolite sequence (central-northern Turkey): A fragment of Middle Jurassic oceanic lithosphere within the Intra-Pontide suture zone. Ofioliti, 37 (2), 77-92.

Göncüoğlu, M.C., Marroni, M., Pandolfi, L., Ellero, A., Ottria, G., Catanzariti, R., Tekin, U.K. and Sayit, K., 2014. The Arkot Dağ Mélange in Araç area, Central Turkey: Evidence of its origin within the geodynamic evolution of the Intra-Pontide suture zone. Journal of Asian Earth Sciences, 85, 117139.

Grenier, G.O.G., 1969. Recent benthic foraminifera, environmental factors controlling their deposition. Nature, 223, 168-170.

Güven, A., 1977. Stratigraphy and sedimentology of Eocene formations, Karabük area, Turkey. Ph. D. Thesis, University of Wales, Swansea, 307p.

Hallock, P. and Glenn, E.C., 1986. Larger Foraminifera: A Tool for paleoenvironmental analysis of Cenozoic carbonate depositional facies. Palaios, 1, 55-64.

Hottinger, L. 1960. Recherches sur les alveolines du Paléogene et de I'Eocene. Mémoires Suisses de Paléontologie, 75-76, 1-236.

Hottinger,L., 1977. Foraminiféres Operculiniformes. Mémoirs du Museum d'Histoire Naturelle, 40, 1-159.

Hottinger, L., 1997. Shallow benthic foraminiferal assemblages as signals for depth of their deposition and their limitations. Bulletin de la Société Géologique France, 168/4, 491-505.

Hottinger, L. and Dreher, D., 1974. Differentiation of protoplasm in Nummulitidae (Foraminifera) from Elat, Red Sea. Marine Biology, 25, 41-61.

Hottinger, L., 2014. Rotaliid Foraminifera from the Western and Central Neotethys. Ed: Davide Bassi, p.196, Springer.

Kennedy, W. J., Tunoğlu, C., Walaszczyk, I and Ertekin, İ.K., 2007. Ammonite and inoceramid bivalve faunas from the Davutlar Formation of the Devrekani-Kastamonu area, northern Turkey, and their biostratigraphical significance. Cretaceous Research, 28 (6), 861-894.

Larsen, A.R., 1976. Studies of Recent Amphistegina: taxonomy and some ecological aspects. Israel Journal Earth Science, 25, 1-26.

Lutherbacher, H.P. 1970. Environmental distribution of early Tertiary microfossils, Tremp Basin, Northeastern Spain. ESSO Production ResearchEuropean Laboratories, 46p.

Murray, J.M., 1973. Distribution and ecology of living benthic foraminiferids. New York, Crane, Russak and Co., $274 \mathrm{p}$. 
Okay, A.I., Tüysüz, O., 1999. Tethyan Sutures of northern Turkey. In: Durand, B., Jolivet, L., Hovarth, F., Séranne, M. (Eds.), The Mediterranean Basins: Tertiary extension within the Alpine Orogen. Geological Society of London Special Publication 156, 475-515.

Özgen-Erdem, N., 2008. Akçataş-Cebeci yöresinin (KB Tosya-GD Kastamonu) Tanesiyen-İlerdiyen bentik foraminifer biyostratigrafisi. MTA Dergisi, 137, 67-77.

Özgen-Erdem, N., 2010. Cyclopertorbitolites, a new Soritid (Foraminifera) from the Ilerdian-Cuisian sediments of the Eskişehir and Kastamonu regions (Turkey). Paleontological Journal, 44 (3), 243252.

Özgen-Erdem, N., İnan, N., Akyazı, M. and Tunoğlu C., 2005. Benthonic foraminiferal assemblages and microfacies analysis of Paleocene-Eocene carbonate rocks in the Kastamonu region, Northern Turkey. Journal of Asian Earth Sciences, 25 (3), 403-417.

Özgen-Erdem, N., Akyazı, M. and Karabaşoğlu, A. 2007. Biostratigraphic interpretation and systematics of Alveolina assemblages from the Ilerdian-Cuisian limestones of southern Eskişehir, Central Turkey. Journal of Asian Earth Sciences, 29 (5-6), 911-927.

Özgen-Erdem, N. and Radoicic, R., 2009. Anatoliacodium gen. nov. (Halimedaceae, green algae) from the Ilerdian-Cuisian in the Eskişehir region (Western Central Turkey). Geologica Carpathica, 60(4), 307-318.

Özgen-Erdem, N. and Radoicic, R., 2014. Clypeina? tekini sp. nov. (Dasycladalean Dasycladacean green algae) from the Early Eocene in the Eskişehir Region (Western Central Turkey), Archives des Sciences, 67, 119-124.

Radoicic, R and Özgen-Erdem, N., 2011. New Data on the Dasycladales from the Lower Eocene of Seyitgazi Region, Eskişehir, Central Turkey. Turkish Journal of Earth Science, 20, 213-242.

Radoicic, R. and Özgen-Erdem, N., 2014. A new Dasycladalean algae from the Lower Eocene of the Seyitgazi Region, Central Turkey: Belzungia barattoloi sp. nov. Acta Palaeontologica Romaniae, 10 (1-2), 5-14.

Reis, Z. and Hottinger, L., 1984. The Gulf of Aqaba, Ecological Micropaleontology. Springer-Verlag, $354 \mathrm{p}$.

Sağular, E.K., Tunoğlu, C. ve Batman, B. 1991. Çağlayan Formasyonu'unda (Alt Kretase?, Orta Pontidler) nannoplanktonlara bağlı biyostratigrafik bulgular. A. Suat Erk Simpozyumu 2-5 Eylül 1991, Bildirileri, 115-128.

Saner, S., Taner, I., Aksoy, Z., Siyako, M. ve Bürkan, K., 1979. Karabük-Safranbolu Bölgesinin Jeolojisi. TPAO Rap. No. 1322.

Sirel, E., 1976a. Description of six new species of the Alveolina found in the south of Polatll (SW Ankara) region. Bulletin of the Geological Society of Turkey, 19 (1), 19-22.

Sirel, E., 1976b. Polatlı (GB Ankara) güneyinde bulunan Alveolina, Nummulites, Ranikothalia ve Assilina cinslerinin bazı türlerinin sistematik incelemeleri. Türkiye Jeoloji Bülteni, 19 (2), 89102.

Sirel, E., 2015. Reference sections and key localities of the Paleogene stages and discussion C-T, P-E, and E-O boundaries by the very shallow-shallow water foraminifer in Turkey. Ankara University, Faculty of Engineering, Department of Geological Engineering, $171 \mathrm{p}$.

Sirel, E. and Acar, Ş., 2008. Description and biostratigraphy of the Thanetian-Bartonian Glomalveolinids and Alveolinids of Turkey. TMMOB Jeoloji Mühendisleri Odası yayınları $103,265 \mathrm{~s}$.

Şengün, M., Keskin, H., Akçaören, F., Altun, İ., Sevin, M., Akat, U., Armağan, F. ve Acar, Ş., 1990. Kastamonu yöresinin jeolojisi ve Paleotetisin evrimine ilişkin sınırlamalar. Türkiye Jeoloji Bülteni, 33, 1-16.

Tunoğlu, C., Ertekin, İ.K., 2005. Kretase - Paleosen yaşlı Davutlar formasyonunun (Devrekani/Kastamonu) ostrakoda biyostratigrafisi ve kronostratigrafisi. TÜBİTAK-YDABAG Projesi:101Y013 (yayımlanmamış). 
Tunoğlu, C., Bardet, N., 2006. Mosasaurus hoffmanni Mantell, 1829: Türkiye'de, Geç Kretase dönemine ait ilk deniz sürüngeninin keşfi. Türkiye Jeoloji Bülteni, 49(1), 11-24.

Tuzcu S. ve Babayiğit, S. 1998. Üst Jura yaşl1 Donacosmilia corallina de Foramente Pin Türkiye'de (Araç-Daday, Kastamonu) bulunuşu. Türkiye Jeoloji Bülteni, 41(1), 99-107.

Tüysüz, O., Aksay, A., Yiğitbaş, E., 2004, Batı Karadeniz Bölgesi Litostratigrafi Birimleri. Maden Tetkik ve Arama Genel Müdürlüğü, Stratigrafi Komitesi Litostratigrafi Birimleri Serisi-1, Ankara, 92s.

Yergök, A. F., Akman, Ü., İplikçi, E., Karabalık, N. N., Keskin, I., Mengi, H., Umut, M., Armağan, F., Erdoğan, K., Kaymakçı, H. ve Çetinkaya, A., 1987. Batı Karadeniz Bölgesi'nin jeolojisi (I), MTA Rap. No. 8273.

Yıldız, A., Yeşilyurt, N., Tunoğlu, C. 2007. Eosen yaşlı Seydiler formasyonunun (Kastamonu,
KB Turkiye) planktonik foraminifer, kalkerli nannoplankton biyostratigrafisi, ostrakod topluluğu ve eski ortam yorumu. Yerbilimleri, 28(1), 33-53.

Y1lmaz, O., 1983. Çangal metaofiyolitinin mineralojikpetrografik incelemesi ve metamorfizma koşulları. Yerbilimleri, 10, 45-58.

Yilmaz, Y. ve Tüysüz, O., 1984. Kastamonu-BoyabatVezirköprü-Tosya arasındaki bölgenin jeolojisi (Ilgaz-Kargı masiflerinin etüdü). M.T.A. Raporu, $275 \mathrm{~s}$

\begin{tabular}{|c|c|}
\hline Makale Geliş Tarihi & : 12 Mart 2016 \\
\hline Kabul Tarihi & : 4 Mayıs 2016 \\
\hline Received & : 12 March 2016 \\
\hline Accepted & : 4 May 2016 \\
\hline
\end{tabular}


LEVHA I
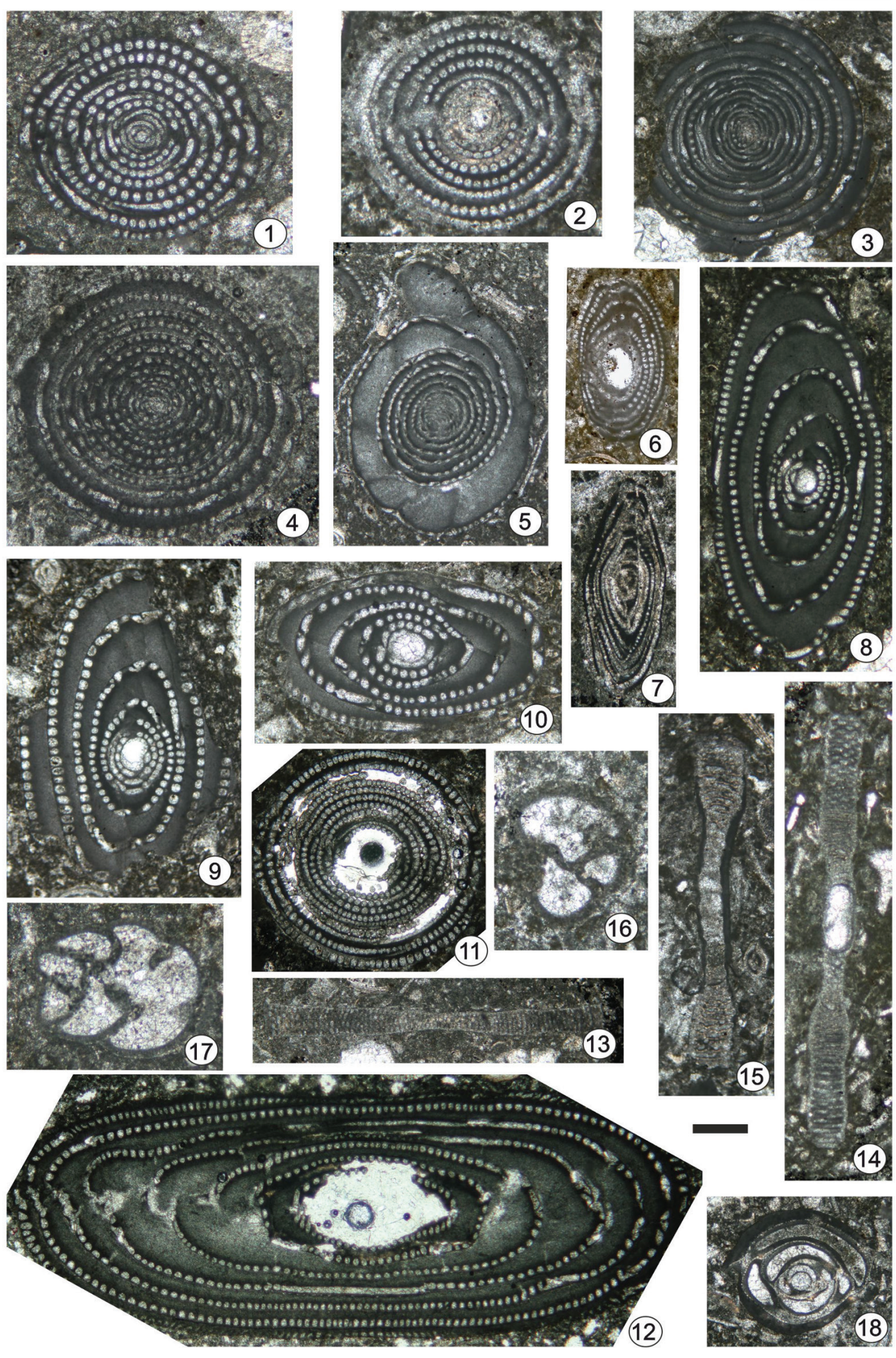

$(13$

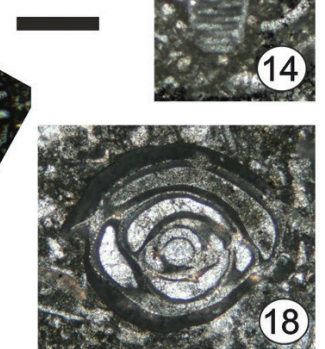




\section{LEVHA 1}

1-2. Glomalveolina lepidula Schwager, eksenel kesitler, (A.11/3, A.7/3)

3-4. Alveolina ankarensis Sirel, 3- ekvatoryal kesit, (A.8/1), 4- eksenel kesit (A.7/1)

5. A. aff. ankarensis Sirel, ekvatoryal kesit (A.14/2)

6. A. erki Acar, eksenel kesit, (A.6/4)

7. A. aff. erki Acar, eksenel kesit, (A.8)

8-10. A. rotundata kazancii Sirel \& Acar, eksenel kesitler, (A.10/3, A.13/4, A.7/4)

11. A. cemali Sirel \& Acar, eksenel kesit, (A.1/4)

12. A. pieroi Sirel \& Acar, eksenel kesit, (A.22)

13-14. Orbitolites complanatus Lamarck, 13- hafif eğik eksenel kesit (A.14/2), 14eksenel kesit (A.7/7)

15- Cyclopertorbitolites tokerae Özgen-Erdem, eksenel kesit (A.7/7)

16-17. Cribrobulimina sp., 16- taban kesiti (A.7/6), eğik dikey kesit (A.19)

18. İdalina sinjarica Grimsdale, eksenel kesit, (A.13/4)

(Ölçek: 1-2: 0,25 mm; 3-12; 13-15, 18: 0.5 mm; 16-17: 0,33 mm)

\section{PLATE 1}

1-2. Glomalveolina lepidula Schwager, axial sections, (A.11/3, A.7/3)

3-4. Alveolina ankarensis Sirel, 3- equatorial section, (A.8/1), 4- axial section (A.7/1)

5. A. aff. ankarensis Sirel, equatorial section (A.14/2)

6. A. erki Acar, axial section, (A. 6/4)

7. A. aff. erki Acar, axial section, (A.8)

8-10. A. rotundata kazancii Sirel \& Acar, axial sections, (A.10/3, A.13/4, A.7/4)

11. A. cemali Sirel \& Acar, axial section, (A.1/4)

12. A. pieroi Sirel \& Acar, axial section, (A.22)

13-14. Orbitolites complanatus Lamarck, 13slightly oblique axial section, (A.14/2), 14axial section (A.7/7)

15- Cyclopertorbitolites tokerae Özgen-Erdem, axial section (A.7/7)

16-17. Cribrobulimina sp., 16- horizontal section (A.7/6), oblique vertical section, (A.19)

18. İdalina sinjarica Grimsdale, axial section, (A.13/4)

(Scale bar: 1-2: 0,25 mm; 3-12; 13-15, 18: 0.5 $\mathrm{mm}$; 16-17: 0,33 mm) 
LEVHA 2
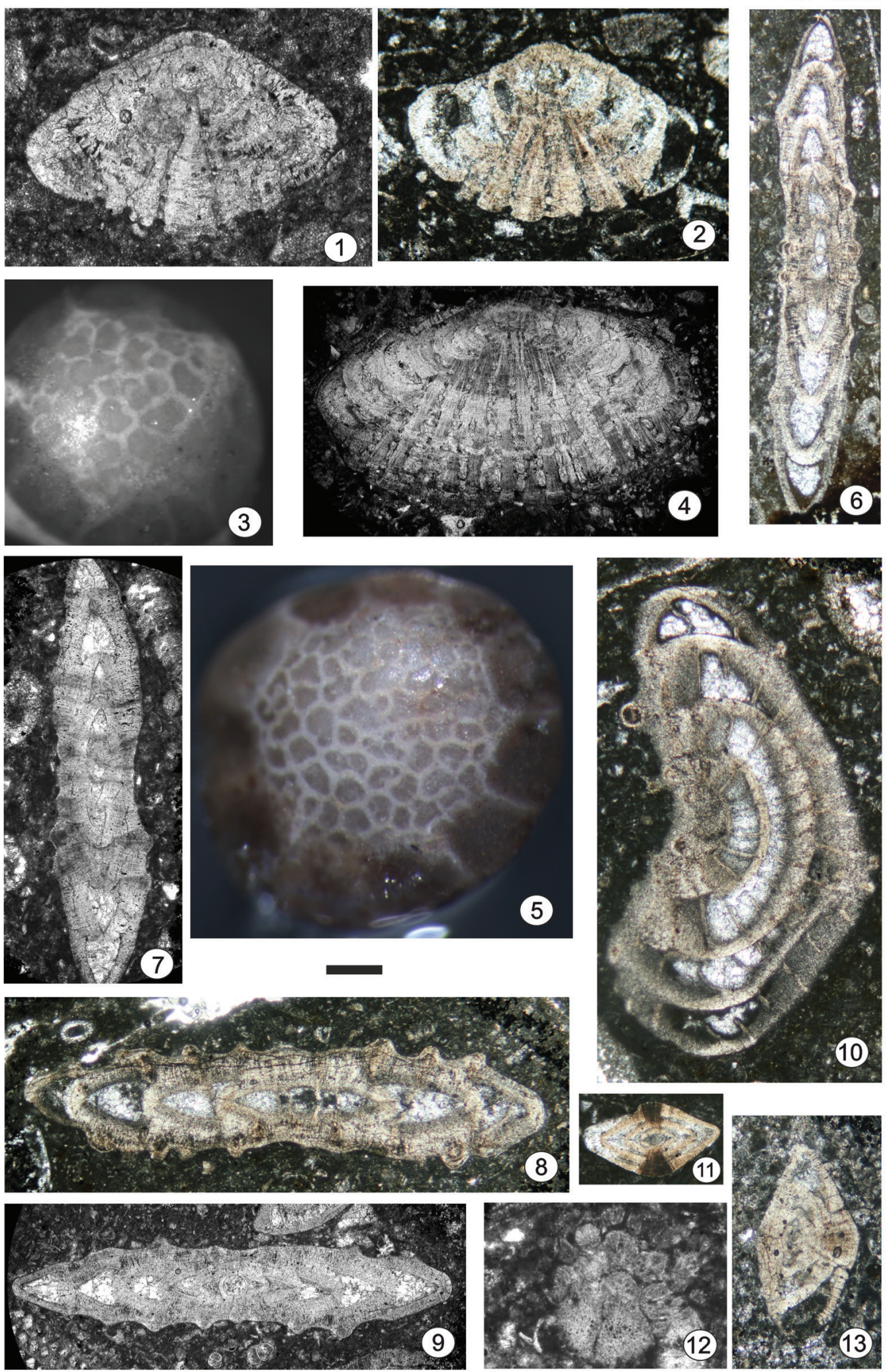


\section{LEVHA 2}

1-3,12. Lockhartia conditi (Nuttall), 1-2. eksenel kesitler, (A.23/1, A.7/1), 3-tane örneğin ombilikal bölgesinden görünüm (A.16/3), 12. Ombilikal pilyeleri gösteren eğik kesit (A.9)

4-5. Lockhartia tipperi (Davies) 4- eksenel kesit, (A.7/1), 5- ombilikal pilyeleri gösteren tane örnek (A.16/7)

6-10. Assilina spinosa (Davies \& Pinfold), 6-9. Eksenel kesitler, (A.29/1, A.9/2, A.29/4, A.27/2), 10- tam olmayan yarı ekvatoryal kesit, (A.29/2)

11. Nummulites sp., eksenel kesit, (A.23/7)

13. Kathina sp., eksenel kesit, (A.7/7)

(Ölçek: 1-5, 12, 13: 0,33 mm; 6-11: 0,5 mm)

\section{PLATE 2}

1-3,12. Lockhartia conditi (Nuttall), 1-2. axial sections, (A.23/1, A.7/1), 3- ventral side of isolated specimen, (A.16/3), 12- oblique section showing ventral piles (A.9)

4-5. Lockhartia tipperi (Davies) 4- axial section, (A.7/1), 5-ventral side of isolated specimen, (A.16/7)

6-10. Assilina spinosa (Davies \& Pinfold), 6-9. Axial sections, (A.29/1, A.9/2, A.29/4, A.27/2), 10- incomplete subequatorial section, (A.29/2)

11. Nummulites sp., axial section, (A.23/7)

13. Kathina sp., axial section, (A.7/7)

(Scale bar: 1-5, 12, 13: 0,33 mm; 6-11: 0,5 mm) 
